\title{
One-Dimensional Aromatic Crystals in Solution VII. Conformational Analysis of Poly $(\beta$-9-anthrylmethyl L-aspartate) in Solution
}

\author{
Masahiko SISIDO, Akira OKAMOTO, ${ }^{*}$ and Yukio IMANISHI* \\ Research Center for Medical Polymers and Biomaterials, \\ Kyoto University, Kyoto 606, Japan \\ *Department of Polymer Chemistry, Kyoto University, \\ Kyoto 606, Japan
}

(Received June 21, 1985)

\begin{abstract}
Main-chain and side-chain helical conformations of a novel aromatic polypeptide, $\operatorname{poly}\left(\beta-9\right.$-anthrylmethyl L-aspartate), poly[ $\left.\mathrm{Asp}\left(\mathrm{OCH}_{2}-9-\mathrm{Ant}\right)\right]$, were studied experimentally and theoretically. A series of random copolymers of $\beta$-9-anthrylmethyl L-aspartate, $\operatorname{Asp}\left(\mathrm{OCH}_{2}-9-\right.$ Ant), and $\gamma$-benzyl L-glutamate, Glu (OBzl), having varying molar ratios were prepared. Their circular dichroism (CD) spectra showed an abrupt change with increasing the mole fraction of $\mathrm{Asp}\left(\mathrm{OCH}_{2}-9\right.$-Ant) from 0.6 to 0.8 , indicating the inversion of the helix sense from a right-handed to a left-handed one. Thus the helix sense of poly[Asp $\left.\left(\mathrm{OCH}_{2}-9-\mathrm{Ant}\right)\right]$ was concluded to be left-handed. Empirical energy calculations were performed on the side-chain conformation of the polypeptide, setting the main chain in a left-handed $\alpha$-helical conformation. Five rotational angles were varied from $0^{\circ}$ to $360^{\circ}$ with an interval of $30^{\circ}$ and seven low-energy side-chain conformations were found. Those conformers were further optimized by the Simplex energy-minimization procedure. Theoretical CD curves were computed for the seven minimum-energy conformations on the basis of the exciton theory. Of the seven candidates two conformers gave reasonable CD pattern, and of the two the lower energy conformer was chosen as the most probable helix conformation of poly$\left[\mathrm{Asp}\left(\mathrm{OCH}_{2}-9-\mathrm{Ant}\right)\right]$ in solution.

KEY WORDS Poly( $\beta$-9-anthrylmethyl L-aspartate) / Helix Sense / Empirical Energy Calculation / Theoretical Circular Dichroism Computation / Exciton Couplet /
\end{abstract}

In the accompanying paper, synthesis and spectroscopic study of a novel aromatic polypeptide, $\operatorname{poly}(\beta$-9-anthrylmethyl L-aspartate), poly[Asp $\left.\left(\mathrm{OCH}_{2}-9-\mathrm{Ant}\right)\right]$, were described. ${ }^{1}$ It was especially noteworthy that the polypeptide showed a strong exciton couplet in the circular dichroism (CD) at the ${ }^{1} \mathrm{~B}_{\mathrm{b}}$ absorption band of anthracene, indicating that the aromatic side chains are regularly arranged along a helical main chian. The observation of the strong CD couplet is the first example in a series of $\operatorname{poly}(\beta$-arylmethyl L-aspartates). In the latter class of polypeptides reported so far, the sidechain aromatic groups have been shown to take random orientations even when the main chain took a helix conformation. ${ }^{2-5}$ In the case of poly[Asp $\left.\left(\mathrm{OCH}_{2}-9-\mathrm{Ant}\right)\right]$, the bulky anthryl groups may interact with each other resulting in a marked reduction of the sidechain conformational freedom and thus leading to a helical side-chain arrangement. In this article, the helix sense of poly[ $\mathrm{Asp}\left(\mathrm{OCH}_{2}-9\right.$ Ant)] was determined experimentally and the side-chain conformation was predicted by the empirical energy calculation and the theoretical CD computation.

The helix sense of poly(alkyl and arylmethyl L-aspartate)s has been reported to be sensitive to the side-chain substituents. ${ }^{6}$ The determination of the helix sense, however, faces diffi- 
culty in the case of aromatic side groups, since chiroptical properties, which are commonly used for the determination of the helix sense, may be markedly affected by the presence of aromatic chromophores. In the present study the helix sense was determined by a "mixing method," 4 i.e., by a gradual addition of $\operatorname{Asp}\left(\mathrm{OCH}_{2}\right.$-9-Ant) unit into poly( $\gamma$-benzyl Lglutamate), poly[Glu(OBzl)], chain which takes a right-handed $\alpha$-helix. An abrupt change in $\mathrm{CD}$ spectrum by the increase of the $\mathrm{Asp}\left(\mathrm{OCH}_{2}-9-\mathrm{Ant}\right)$ content in the statistical copolymer, if observed, would indicate a reversal of the helix sense from the righthanded helix of poly[Glu(OBzl)] to the lefthanded one.

The anthryl side groups are advantageous in determining the side-chain conformation theoretically. First, an empirical conformational energy calculation will be more reliable than that for smaller side groups, since the bulky groups confine their orientations in a very limited conformational space. Second, a theoretical CD calculation based on the exciton theory will be straightforward for such a simple aromatic groups as anthryl, for which the directions and the magnitudes of transition moments have been well known. The empirical energy calculation was carried out for a helical heptamer of $\mathrm{Asp}\left(\mathrm{OCH}_{2}-9-\mathrm{Ant}\right)$ and the theoretical $\mathrm{CD}$ computation was performed on a pentadecamer.

\section{EXPERIMENTAL}

\section{Synthesis of Statistical Copolymers of $\mathrm{Asp}\left(\mathrm{OCH}_{2}-9-\mathrm{Ant}\right)$ and $\mathrm{Glu}(\mathrm{OBzl})$}

The $N$-carboxyanhydrides (NCAs) of Asp $\left(\mathrm{OCH}_{2}\right.$-9-Ant $)$ and $\mathrm{Glu}(\mathrm{OBzl})$ were mixed in dimethylformamide and $n$-hexylamine was added as an initiator. The solution was left for standing for 3-4 days at room temperature until the IR peaks characteristic of the NCAs disappeared. The NCA/amine molar ratio, which is approximately equal to the number average degree of polymerization, was adjust- ed to be 47 . The polymer solution was poured into ether and the precipitate was washed with ether several times. By this procedure, copolymers having different $\mathrm{Asp}\left(\mathrm{OCH}_{2}-9\right.$-Ant $)$ feed contents, i.e., $0.2,0.4,0.6$, and 0.8 , were prepared. The IR peak ratios of $738 \mathrm{~cm}^{-1}$ (anthryl + benzyl) to $699 \mathrm{~cm}^{-1}$. (benzyl) of the copolymers increased with increasing the feed content of aspartate. The GPC analyses of the copolymers showed almost the same elution diagram having a peak at $M \sim 2000$ (column: Shodex AD-803 equibrated in dimethylformamide at $60^{\circ} \mathrm{C}$ ). Since the homopolymer of Asp $\left(\mathrm{OCH}_{2}\right.$-9-Ant $)$ was not soluble in usual solvents, a block copolymer of $\mathrm{Asp}\left(\mathrm{OCH}_{2}-9\right.$ ant) with DL-Glu(OBzl) was prepared as described in the accompanying paper.

\section{Measurements}

CD spectra were recorded on a JASCO J-20 instrument in trimethyl phosphate (TMP) at room temperature.

\section{CONFORMATIONAL ENERGY CALCULATION}

A conformational energy calculation was carried out for a helical heptamer of $\operatorname{Asp}\left(\mathrm{OCH}_{2}-9-\mathrm{Ant}\right)$. The procedure to find out low-energy helical conformations of poly[Asp $\left.\left(\mathrm{OCH}_{2}-9-\mathrm{Ant}\right)\right]$ is shown in Scheme $\mathrm{I}$. The ECEPP system was employed for the energy and structural parameters, ${ }^{7}$ except for those for the 9-anthrylmethyl ester group. The structural parameters employed are shown in Figure 1.

Partial charges of the 9-anthrylmethyl ester group were estimated by a CNDO/ 2 molecular orbital calculation on 9-anthrylmethyl acetate in an all trans conformation. The partial charges employed are listed in Table I.

Since the main chain was found to take a left-handed helix, as will be described later, the conformational calculation was carried out setting the main chain in a left handed $\alpha$-helix $(\phi, \psi, \omega)=\left(57.0^{\circ}, 47.0^{\circ}, 180.0^{\circ}\right)$. First, low- 
Poly(9-anthrylmethyl L-aspartate), Theoretical

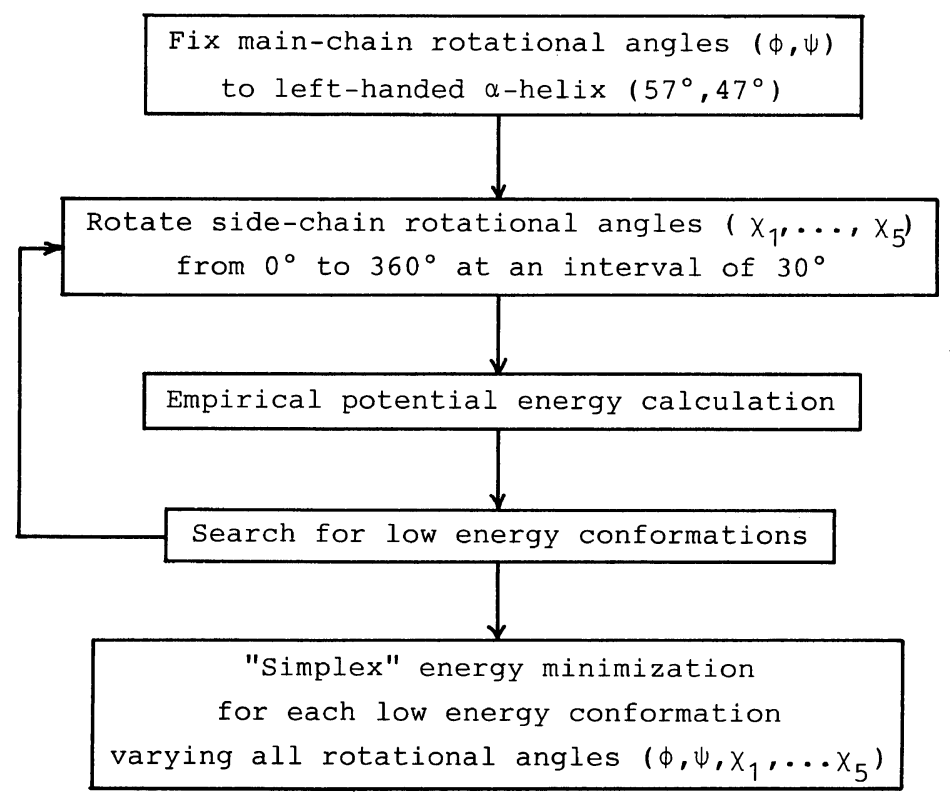

Scheme I. Procedure to find out minimum-energy conformations.

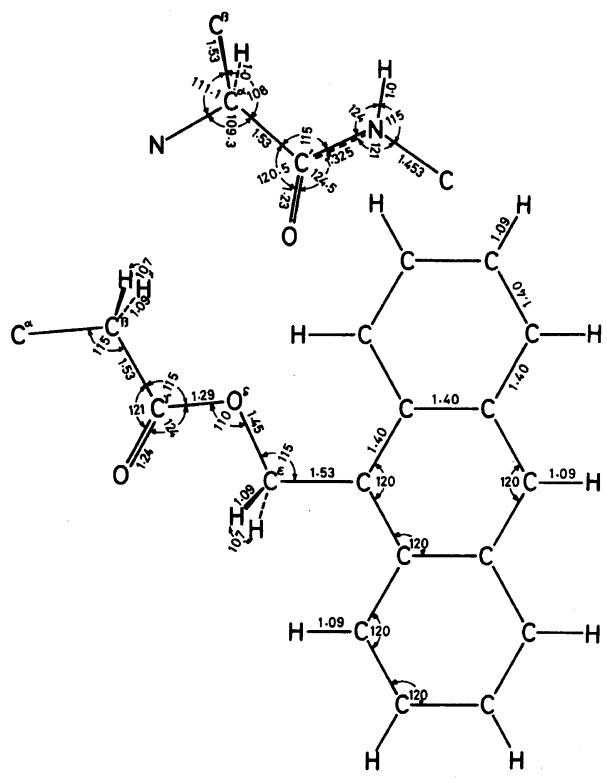

Figure 1. Geometrical parameters of $\mathrm{Asp}\left(\mathrm{OCH}_{2}-9\right.$ Ant) unit.

energy side-chain conformations were searched in the whole side-chain conformational space varying the side-chain rotational angles $\left(\chi_{1}, \chi_{2}, \chi_{3}, \chi_{4}, \chi_{5}\right)$ from $0^{\circ}$ to $360^{\circ}$ with an
Table I. Partial charges on $\mathrm{Asp}\left(\mathrm{OCH}_{2}-9-\mathrm{Ant}\right)$ unit for conformational energy calculation (in esu unit)

\begin{tabular}{lrlr}
\hline \multicolumn{2}{c}{ Atoms in main chain } & \multicolumn{2}{c}{ Atoms in side chain } \\
\hline $\mathrm{N}$ & -0.356 & $\mathrm{C}^{\beta}$ & -0.094 \\
$\mathrm{H}^{\mathrm{N}}$ & 0.176 & $\mathrm{H}^{\beta}$ & 0.055 \\
$\mathrm{C}^{\alpha}$ & 0.064 & $\mathrm{C}^{\gamma}$ & 0.480 \\
$\mathrm{H}^{\alpha}$ & 0.040 & $\mathrm{O}(=\mathrm{C})$ & -0.360 \\
$\mathrm{C}^{\prime}$ & 0.450 & $\mathrm{O}^{\delta}$ & -0.325 \\
$\mathrm{O}$ & -0.384 & $\mathrm{C}^{\varepsilon}$ & 0.100 \\
& & $\mathrm{H}^{\varepsilon}$ & 0.030 \\
\hline
\end{tabular}

Atoms in anthryl group

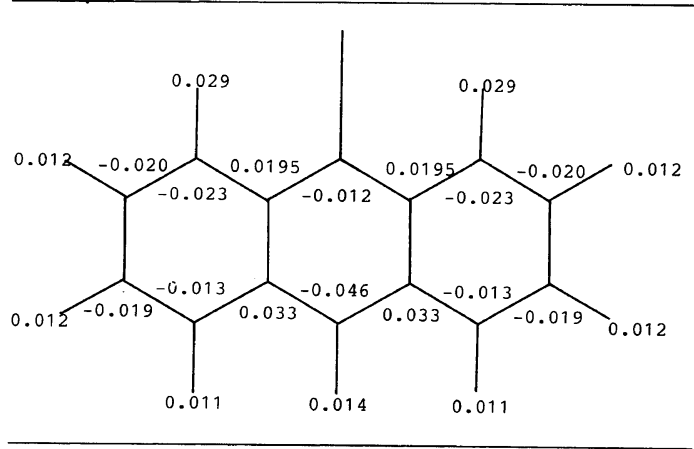


interval of $30^{\circ}$. From the $12^{5}=248832$ conformations, seven independent low-energy conformations were chosen. Starting from the seven low-energy conformers, a "Simplex"8 energy minimization was performed varying the five rotational angles simultaneously and the minimum-energy (ME) conformations were obtained.

\section{THEORETICAL CD CALCULATION}

For the seven ME conformations found by the empirical energy calculation, theoretical $\mathrm{CD}$ was computed on the basis of the exciton theory. ${ }^{9-12}$ The polymer was assumed to be a pentadecamer $(n=15)$ in a regular helical conformation. The procedure is schematically shown in Scheme II.

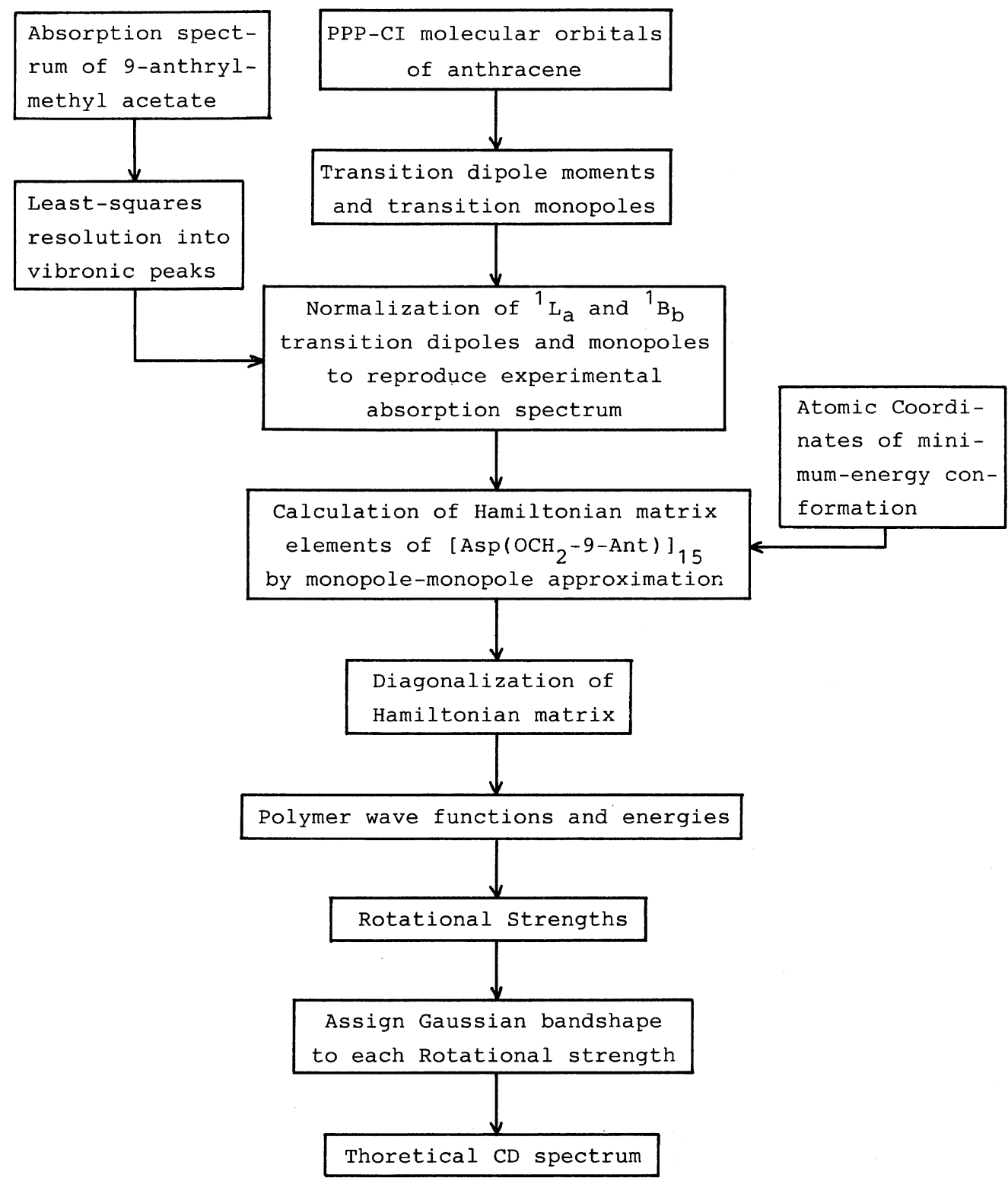

Scheme II. Procedure of theoretical CD calculation. 


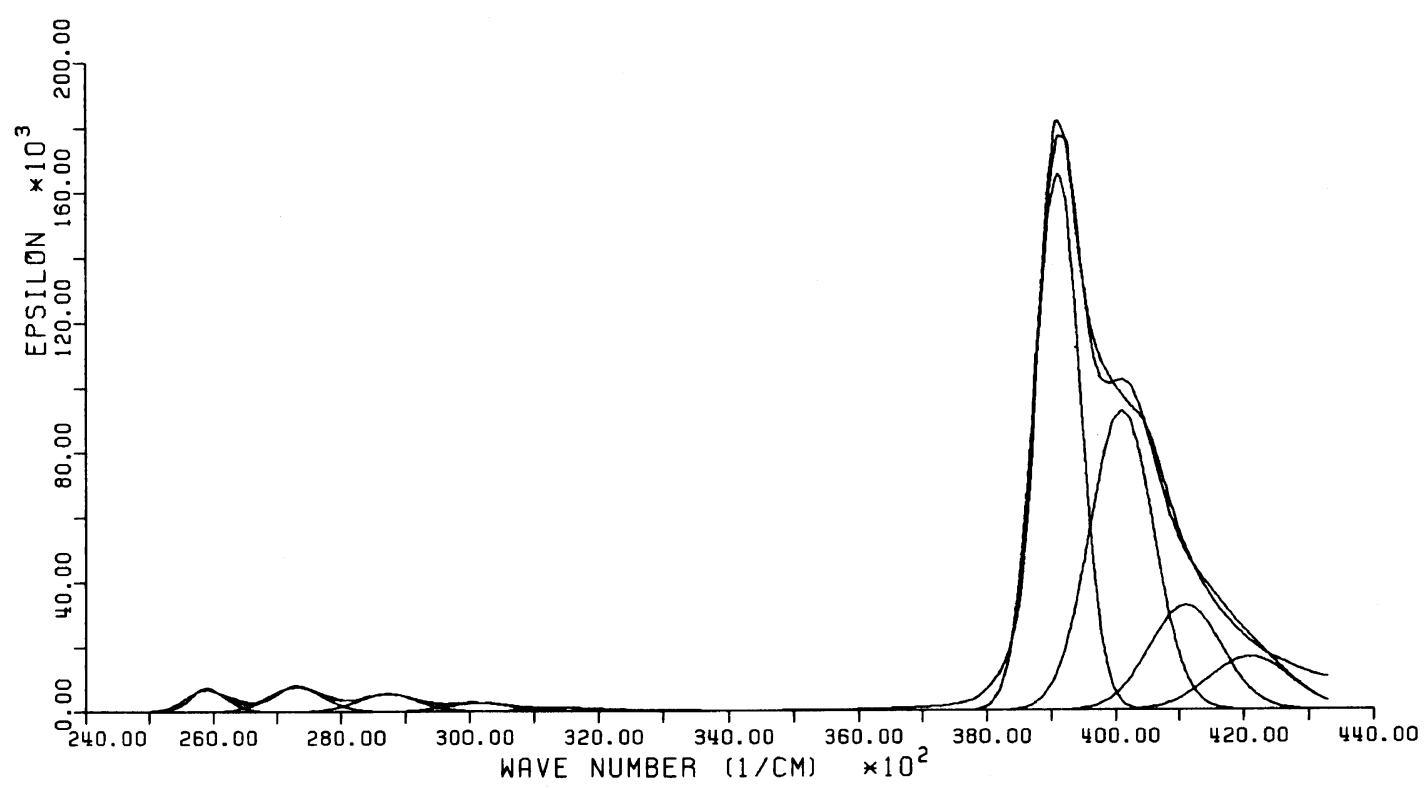

Figure 2. Least-squares resolution of absorption spectrum of 9-anthrylmethyl acetate in trimethyl phosphate into vibronic peaks.

First, a PPP-CI molecular orbital calculation was performed on anthracene and the directions and magnitudes of transition moments for ${ }^{1} \mathrm{G} \rightarrow{ }^{1} \mathrm{~L}_{\mathrm{b}},{ }^{1} \mathrm{G} \rightarrow{ }^{1} \mathrm{~L}_{\mathrm{a}}$, and ${ }^{1} \mathrm{G} \rightarrow{ }^{1} \mathrm{~B}_{\mathrm{b}}$ transitions were calculated. The magnitudes of the transition moments and the transition monopoles were then normalized to reproduce the experimental absorption intensity of 9-anthrylmethyl acetate in trimethyl phosphate. In this computation each vibronic transition observed in the ${ }^{1} \mathrm{~L}_{\mathrm{a}}$ or ${ }^{1} \mathrm{~B}_{\mathrm{b}}$ absorption band is treated as single independent transition having the same direction of the transition moment within the absorption band. ${ }^{11}$ Therefore the experimental absorption spectrum was resolved into vibronic peaks having Gaussian bandshapes with the same peak width within each absorption band. The result of the least-squares resolution is shown in Figure 2 and the oscillator strengths and peak positions are listed in Table II. The peak position of the $0-0$ transition of the ${ }^{1} \mathrm{~L}_{\mathrm{b}}$ band was somewhat arbitrarily determined to be $28000 \mathrm{~cm}^{-1}$, taking the peak positions of benzene, naphthalene, and pentacene into con-
Table II. Peak positions and oscillator strengths of the vibronic peaks of 9-anthrylmethyl acetate in trimethyl phosphate (refractive index $=1.40$ )

\begin{tabular}{ccc}
\hline \multirow{2}{*}{$\begin{array}{c}\text { Electronic } \\
\text { transition }\end{array}$} & Peak position & $\begin{array}{c}\text { Oscillator } \\
\text { strength }\end{array}$ \\
\cline { 2 - 2 } & $\mathrm{cm}^{-1}$ & \\
\hline${ }^{1} \mathrm{~L}_{\mathrm{b}}$ & 28000 & 0 \\
& 29400 & 0 \\
& 30800 & 0 \\
& 32200 & 0 \\
${ }^{1} \mathrm{~L}_{\mathrm{a}}$ & 33600 & 0 \\
& 25887 & 0.03298 \\
& 27302 & 0.04904 \\
& 28717 & 0.03800 \\
& 30131 & 0.01997 \\
${ }^{1} \mathrm{~B}_{\mathrm{b}}$ & 31547 & 0.00784 \\
& 32962 & 0.00276 \\
& 39093 & 0.87744 \\
& 40093 & 0.68791 \\
& 41093 & 0.27525 \\
& 42093 & 0.15720 \\
\hline
\end{tabular}

sideration. Since the ${ }^{1} \mathrm{~L}_{\mathrm{b}}$ transition is forbidden, small variation in the ${ }^{1} \mathrm{~L}_{b}$ peak positions does not affect the final results. The transition monopoles employed in this calcu- 
Table III. Monopole charges for anthryl transitions $\mathrm{s}^{\mathrm{a}, \mathrm{b}}$

\begin{tabular}{|c|c|c|c|c|c|c|}
\hline Center ${ }^{\mathrm{c}}$ & ${ }^{1} \mathrm{~L}_{\mathrm{b}}$ & ${ }^{1} \mathrm{~L}_{\mathrm{a}}$ & ${ }^{1} B_{b}$ & ${ }^{1} \mathrm{~L}_{\mathrm{b}}{ }^{1} \mathrm{~L}_{\mathrm{a}}$ & ${ }^{1} \mathrm{~L}_{\mathrm{b}}{ }^{1} \mathrm{~B}_{\mathrm{b}}$ & ${ }^{1} \mathrm{~L}_{\mathrm{a}}{ }^{1} \mathrm{~B}_{\mathrm{b}}$ \\
\hline 1 & 0.0 & -0.2458 & -0.2699 & 0.1218 & 0.0768 & 0.0 \\
\hline 2 & 0.0 & 0.2890 & -0.0538 & -0.0302 & -0.2254 & 0.0 \\
\hline 3 & 0.0 & -0.1957 & -0.1575 & 0.0850 & 0.3809 & 0.0 \\
\hline 4 & 0.0 & 0.4915 & 0.0 & 0.0 & -0.4644 & 0.0 \\
\hline 5 & 0.0 & -0.1957 & 0.1575 & -0.0850 & 0.3809 & 0.0 \\
\hline 6 & 0.0 & 0.2890 & 0.0538 & 0.0302 & -0.2254 & 0.0 \\
\hline 7 & 0.0 & -0.2458 & 0.2699 & -0.1218 & 0.0768 & 0.0 \\
\hline 8 & 0.0 & 0.2458 & 0.2699 & 0.1218 & 0.0768 & 0.0 \\
\hline 9 & 0.0 & -0.2890 & 0.0538 & -0.0302 & -0.2254 & 0.0 \\
\hline 10 & 0.0 & 0.1957 & 0.1575 & 0.0850 & 0.3809 & 0.0 \\
\hline $11^{\circ}$ & 0.0 & -0.4915 & 0.0 & 0.0 & -0.4644 & 0.0 \\
\hline 12 & 0.0 & 0.1957 & -0.1575 & -0.0850 & 0.3809 & 0.0 \\
\hline 13 & 0.0 & -0.2890 & -0.0538 & 0.0302 & -0.2254 & 0.0 \\
\hline 14 & 0.0 & 0.2458 & -0.2699 & -0.1218 & 0.0768 & 0.0 \\
\hline
\end{tabular}

${ }^{a}$. Monopoles are located $1.0806 \AA$ above and below the aromatic ring. Charges given are those for each monopole in units of $10^{-10}$ esu.

${ }^{b}$ Monopoles charges for ${ }^{1} \mathrm{~L}_{\mathrm{a}}$ and ${ }^{1} \mathrm{~B}_{\mathrm{b}}$ transitions are the results of PPP-CI calculation normalized to reproduce the observed oscillator strength of 9-anthrylmethyl acetate in trimethyl phosphate. For other transitions the PPP-CI results are given.

c Numbering of the carbon atoms is shown below.<smiles>CC1C2CCCCC2CC2CCCCC21</smiles>

lation are listed in Table III.

Besides the transitions in anthryl group, $\pi \pi^{*}$ and $n \pi^{*}$ transitions of main-chain amide bond. were taken into consideration. The peak positions, transition moments, and transition monopoles of the two amide transitions are the same as those used in Woody's paper. ${ }^{13}$ Since 17 vibronic transitions (amide $n \pi^{*}, \pi \pi^{*}$, anthryl ${ }^{1} \mathrm{~L}_{\mathrm{b}} \times 5,{ }^{1} \mathrm{~L}_{\mathrm{a}} \times 6$, and $\left.{ }^{1} \mathrm{~B}_{\mathrm{b}} \times 4\right)$ are taken into consideration for an $\mathrm{Asp}\left(\mathrm{OCH}_{2}\right.$-9-Ant) unit, a Hamiltonian matrix of $255 \times 255$ was constructed for a pentadecamer of Asp$\left(\mathrm{OCH}_{2}-9-\mathrm{Ant}\right)$. The nondiagonal matrix elements were calculated from monopole-monopole interactions between the corresponding two transitions. The diagonal terms are those listed in Table II. The polymer wavefunctions and energies obtained after the diagonalization of the Hamiltonian matrix were used to calculate the rotational strengths.
For each rotational strength a Gaussian peak shape with a peak width of $10 \mathrm{~nm}$ was given to draw a CD spectrum.

\section{RESULTS AND DISCUSSION}

\section{Helix Sense of Poly[ $\left.\mathrm{Asp}\left(\mathrm{OCH}_{2}-9-\mathrm{Ant}\right)\right]$}

Figure 3 shows $C D$ spectra of the series of statistical copolymers of $\mathrm{Asp}\left(\mathrm{OCH}_{2}-9\right.$-Ant $)$ and $\mathrm{Glu}(\mathrm{OBzl})$ having different molar ratios. The copolymer with $\mathrm{Asp}\left(\mathrm{OCH}_{2}-9-\mathrm{Ant}\right)$ content of 0.2 shows a typical CD pattern of a right-handed $\alpha$-helix at the absorption band of amide group $(200-230 \mathrm{~nm})$. The negative CD decreases its intensity as the aspartate content increases and eventually becomes positive for the homopolymer of $\mathrm{Asp}\left(\mathrm{OCH}_{2}-9-\mathrm{Ant}\right)$. The inversion of $\mathrm{CD}$ signal is also observed in the absorption band of anthryl ${ }^{1} B_{b}$ transition $(260 \mathrm{~nm})$ at the aspartate content between 0.6 


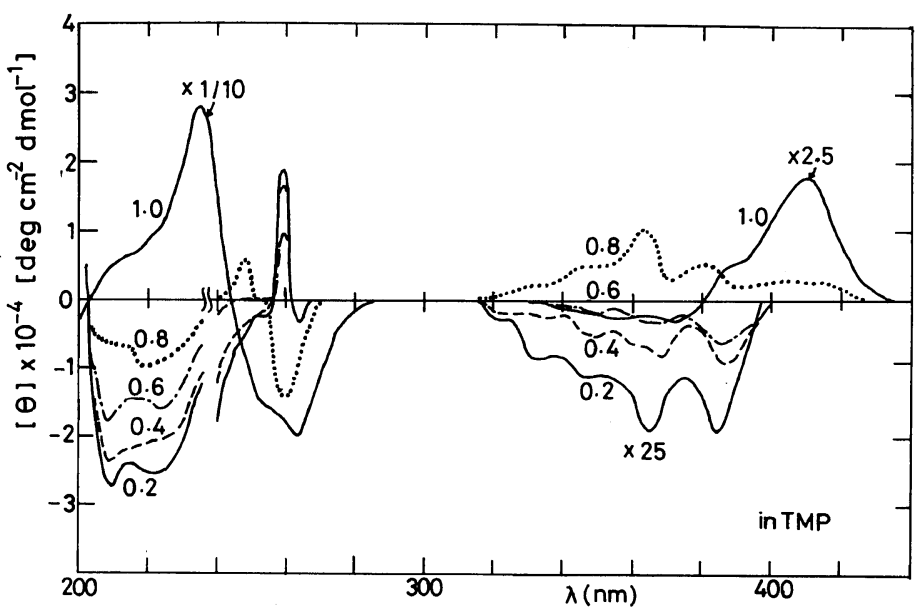

Figure 3. $\mathrm{CD}$ spectra of copoly[Asp $\left.\left(\mathrm{OCH}_{2}-9-\mathrm{Ant}\right)-r-\mathrm{Glu}(\mathrm{OBzl})\right]$ in trimethyl phosphate at room temperature. $[$ Asp $]=2.7 \times 10^{-4} \mathrm{moll}^{-1}$ at $\lambda>300 \mathrm{~nm}, 1.9 \times 10^{-5} \mathrm{moll}^{-1}$ at $\lambda<300 \mathrm{~nm}$. The molar ellipticity is calculated with respect to the concentration of amide bond at $\lambda<240 \mathrm{~nm}$ and with respect to the concentration of anthryl group at $\lambda>240 \mathrm{~nm}$.

and 0.8. Thus it is concluded that the homopolymer of $\mathrm{Asp}\left(\mathrm{OCH}_{2}-9-\mathrm{Ant}\right)$ takes a lefthanded helix in TMP solution.

At the ${ }^{1} \mathrm{~L}_{\mathrm{a}}$ absorption band $(320-400 \mathrm{~nm})$, the negative $\mathrm{CD}$ observed for glutamate-rich copolymers was inverted to a positive signal at the aspartate content between 0.6 and 0.8 . However, the homopolymer of $\mathrm{Asp}\left(\mathrm{OCH}_{2}-9\right.$ Ant) shows negative $\mathrm{CD}$ in this region. This complexity may be explained by the contribution of $\mathrm{CD}$ signal from the ground-state dimer or aggregate of the anthryl groups which shows a marked positive $C D$ at longer wavelengths than $400 \mathrm{~nm} .{ }^{1}$ Hence, the intrinsic CD signal of the ${ }^{1} \mathrm{~L}_{\mathrm{a}}$ band may be positive.

The left-handed helicity has been observed in benzyl and 1-naphthylmethyl derivatives of polyaspartates. ${ }^{3,4}$ Therefore, the conformation of 9-anthrylmethyl derivative lies on a straightforward extension of arylmethyl esters of polyaspartate.

\section{Conformational Energy Calculation}

Since the main chain of poly[ $\mathrm{Asp}\left(\mathrm{OCH}_{2}-9\right.$ Ant)] was found to take a left-handed helix, conformational energy calculation was carried out for a left-handed $\alpha$-helical main chain. The
Table IV. Minimum-energy side-chain conformations of poly(9-anthrylmethyl L-aspartate) with left-handed $\alpha$-helical main chain $\left(\phi=57^{\circ}, \psi=47^{\circ}, \omega=180^{\circ}\right)$

\begin{tabular}{lcrcccc}
\hline Number & $\chi_{1}$ & $\chi_{2}$ & $\chi_{3}$ & $\chi_{4}$ & $\chi_{5}$ & $E / \mathrm{kcal} \mathrm{mol}^{-1 \mathrm{a}}$ \\
\hline $1 \mathrm{M}$ & 313 & 123 & 187 & 176 & 90 & 0.0. \\
$2 \mathrm{M}$ & 309 & 243 & 173 & 183 & 90 & 1.82 \\
$3 \mathrm{M}$ & 190 & 24 & 191 & 175 & 90 & 1.66 \\
$4 \mathrm{M}$ & 304 & 312 & 207 & 168 & 90 & 1.77 \\
$5 \mathrm{M}$ & 194 & 181 & 171 & 181 & 90 & 3.96 \\
$6 \mathrm{M}$ & 302 & 65 & 119 & 151 & 89 & 3.32 \\
$7 \mathrm{M}$ & 310 & 312 & 259 & 188 & 91 & 5.03 \\
\hline
\end{tabular}

a (Empirical energy for the heptamer measured from 1M conformation) $/ 7$.

minimum-energy conformations found in the side-chain conformational space of $\left(\chi_{1}, \chi_{2}, \chi_{3}\right.$, $\left.\chi_{4}, \chi_{5}\right)$ are listed in Table IV. The side-chain rotational angles listed in Table IV can be interpreted on the basis of the $\mathrm{t}-\mathrm{g}^{+}-\mathrm{g}^{-}$rotational isomeric model. Two regions are allowed for $\chi_{1}$. One is around $300^{\circ}$, which corresponds to the $\mathrm{g}^{+}$position of the $\mathrm{C}^{\gamma}$ atom with respect to the nitrogen atom of the main chain. Another region allowed for $\chi_{1}$ is around $190^{\circ}$, which is near the trans position of the $\mathrm{C}^{\gamma}$ atom with respect to the main-chain nitrogen 
atom. A variety of rotational positions are allowed around the $\mathrm{C}^{\beta}-\mathrm{C}^{\gamma}$ bond. The allowed regions of $\chi_{2}$ distribute among $\mathrm{t}\left(0^{\circ}\right), \mathrm{g}^{+}\left(240^{\circ}\right)$, and $\mathrm{g}^{-}\left(120^{\circ}\right)$ positions with respect to the ester carbonyl oxygen and the $\mathrm{C}^{\alpha}$ atom, and $\mathrm{t}$ $\left(180^{\circ}\right), \mathrm{g}^{+}\left(60^{\circ}\right)$, and $\mathrm{g}^{-}\left(300^{\circ}\right)$ positions with respect to $\mathrm{O}^{\delta}$ and $\mathrm{C}^{\alpha}$. The ester linkage is fixed nearly to trans $\left(\chi_{3}=180^{\circ}\right)$, with exceptions (6M and 7M) for relatively high energy conformations. It is somewhat surprising that $\chi_{4}$ and $\chi_{5}$ are fixed to trans and staggared conformations, respectively. This indicates that in the low-energy conformations, the side chain-side chain and the side chain-main chain interactions are not important in determining the side-chain conformations and that the terminal portion of the side chain is in an intact conformation irrespective of the confor- mations in other parts of the polymer. The typical side chain conformation is illustrated in Figure 4.

\section{Theoretical CD Computation}

For the seven minimum-energy conformations listed in Table IV, theoretical CD

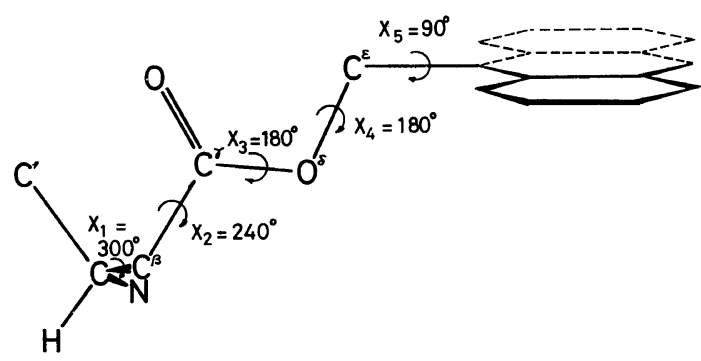

Figure 4. Geometry of minimum-energy (2M) sidechain conformation.

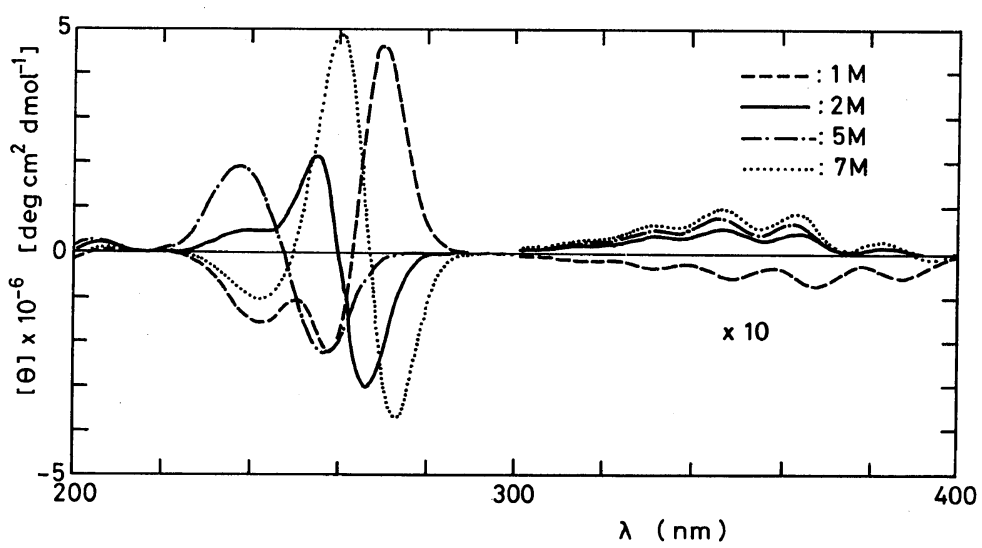

(a)

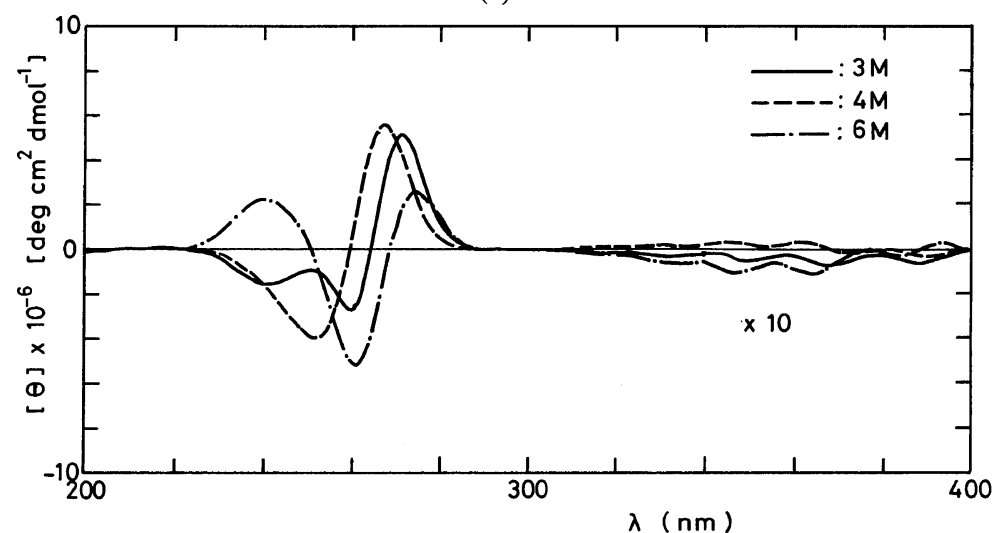

(b)

Figure 5. Theoretical CD spectra of minimum-energy conformations. a: $1 \mathrm{M}, 2 \mathrm{M}, 5 \mathrm{M}$, and $7 \mathrm{M}$. b: $3 \mathrm{M}$, $4 \mathrm{M}$, and $6 \mathrm{M}$. 

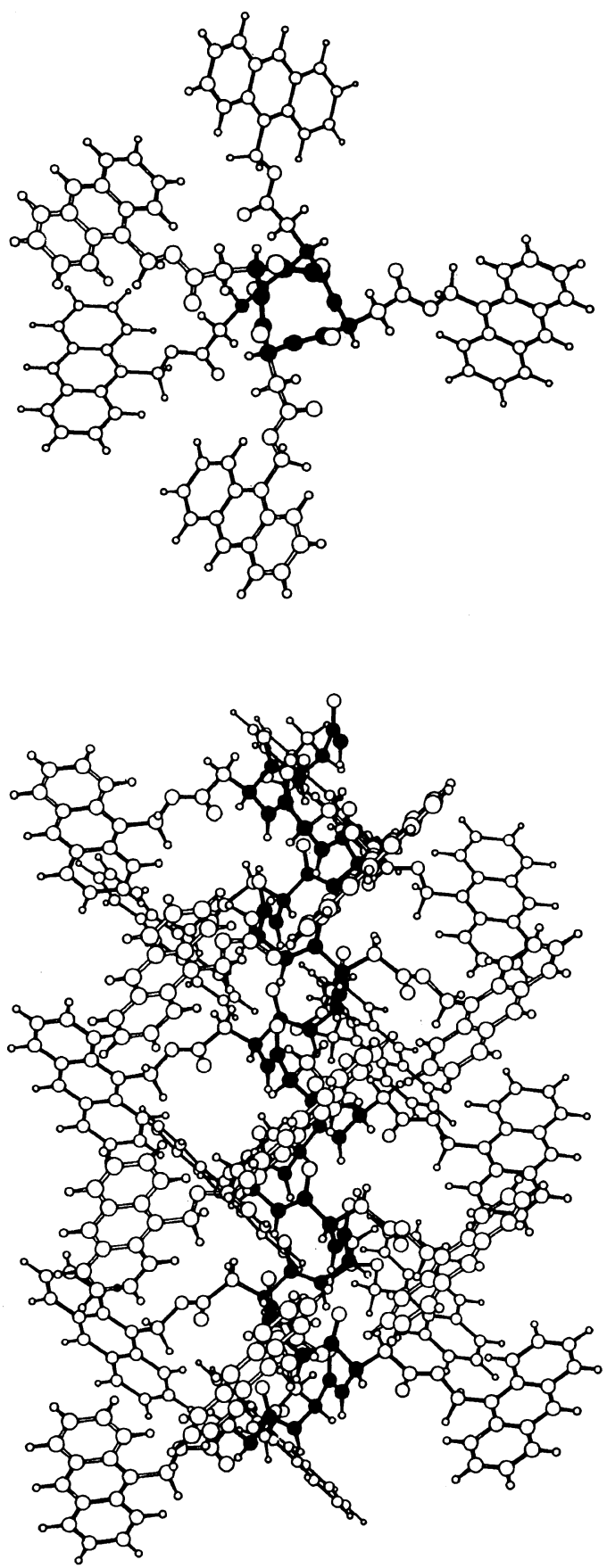

Figure 6. Top and side view of poly[Asp $\left(\mathrm{OCH}_{2}-9\right.$ Ant)] in $2 \mathrm{M}$ conformation. NAMOD molecular display program (ref 14) was used. spectra were computed on the basis of the exciton model. The results are shown in Figure 5. The theoretical CD spectra should be compared with the experimental CD shown in Figure 3 (solid curve). Only two conformers ( $2 \mathrm{M}$ and $5 \mathrm{M}$ ) were found to reproduce the experimental exciton splitting at the ${ }^{1} \mathrm{~B}_{\mathrm{b}}$ absorption band. Both of the two conformers predict a positive $C D$ at the ${ }^{1} \mathrm{~L}_{\mathrm{a}}$ absorption band. The positive sign does not contradict with the experimental data, if a large contribution from the ground state dimer or aggregates is considered, as described above. Conformation $7 \mathrm{M}$ also predicts a positive (shorter wavelength)-negative (longer wavelength) exciton couplet, but the peak positions are far from the experimental ones.

Of the two probable candidates $2 \mathrm{M}$ and $5 \mathrm{M}$, the $2 \mathrm{M}$ conformation is more likely, since the conformation energy calculated for $2 \mathrm{M}$ is considerably lower than that for $5 \mathrm{M}$ by $2.14 \mathrm{kcal}$ per residue. The molecular structure of the $2 \mathrm{M}$ conformation is displayed in Figure $6 .{ }^{14}$

The intensity of the theoretical CD spectra is larger than that of the experimental one by about an order of magnitude. This may be partly because of an imperfect helix structure of poly[Asp $\left.\left(\mathrm{OCH}_{2}-9-\mathrm{Ant}\right)\right]$ in solution. Actually, the fluorescence-detected circular dichroism (FDCD) indicated that the CD may increase its intensity by more than twice, if one can measure the $\mathrm{CD}$ of helical part of the polypeptide exclusively. ${ }^{1}$ The present calculation predicted the conformation of the helical part of poly[Asp $\left.\left(\mathrm{OCH}_{2}-9-\mathrm{Ant}\right)\right]$.

\section{CONCLUSIONS}

The helix sense of poly[Asp $\left.\left(\mathrm{OCH}_{2}-9-\mathrm{Ant}\right)\right]$ was determined to be left-handed. The most probable conformation predicted from the conformational energy and the theoretical CD calculations is that illustrated in Figure 6 (conformation 2M). 


\section{REFERENCES}

1. M. Sisido, A. Okamoto, S. Egusa, and Y. Imanishi, Polym. J., 17, 1253 (1985).

2. M. Hashimoto, Bull. Chem. Soc. Jpn., 39, 2713 (1966).

3. H. Nomori, N. Tsuchihashi, S. Takagi, and M. Hatano, Bull. Chem. Soc. Jpn., 48, 2522 (1975).

4. A. Ueno, T. Ishiguro, F. Toda, K. Uno, and Y. Iwakura, Biopolymers, 14, 353 (1975).

5. A. Ueno, T. Osa, and F. Toda, Macromolecules, 10, 130 (1977).

6. Y. Konishi and M. Hatano, J. Polym. Sci., Polym. Lett. Ed., 14, 351 (1976).

7. F. A. Momany, R. F. McGuire, A. W. Burgess, and
H. A. Scheraga, J. Phys. Chem., 79, 2361 (1975).

8. J. A. Nelder and R. Mead, Computer J., 7, 308 (1965).

9. R. W. Woody, J. Polym. Sci., Macromol. Rev., 12, 181 (1977).

10. M. Sisido, S. Egusa, and Y. Imanishi, J. Am. Chem. Soc., 105, 1041 (1983).

11. M. Sisido, S. Egusa, and Y. Imanishi, J. Am. Chem. Soc., 105, 4077 (1983).

12. M. Sisido and Y. Imanishi, Macromolecules, 18, 890 (1985).

13. R. W. Woody, J. Chem. Phys., 49, 4797 (1968).

14. Y. Beppu, "Quantum Chemistry Program Exchange," University of Indiana, Bloomington, Indiana, No. 370, 1979. 